\title{
DAMPAK PEMBELAJARAN KOOPERATIF TIPE STAD TERHADAP HASIL BELAJAR BIOLOGI SISWA SMPN 3 BATANG ANAI PARIAMAN
}

\author{
Gustina Indriati \\ Program Studi Pendidikan Biologi STKIP \\ PGRI Sumatera Barat \\ E-mail: gustina indriati@yahoo.com
}

Evrialiani Rosba

STKIP PGRI Sumatera Barat

E-Mail: rosba.evrialiani@gmail.com

Tyara Jayus Mely

STKIP PGRI Sumatera Barat

E-mail: tyara.jayusmely02@gmail.com

\begin{abstract}
Abstrak: The purpose of this research is to figure out the effect of cooperative strategy type STAD with LDS on the students' cognitive domain learning outcomes in Biology class, at the eighth grade of SMPN 3 Batang Anai. The research was an experimental research with Randomised Control Group Postest Only Design. The research instrument was a multiple choice test consisting of 55 test items. The cognitive test result of the experimental group was 70.46, whereas that of the control group was 60.07. $T$ test result shows $t_{\text {count }}(3.34)>t_{\text {table }}(1.68)$. Thus the hypothesis was accepted. It is concluded that the cooperative learning Type STAD with LDS gives an effect on the students' cognitive domain learning outcomes of Biology subject taught to the eighth grads students of SMPN 3 Batang Anai Padang Pariaman regency.
\end{abstract}

Keyword: Activity, Learning outcomes, Cooperative learning model type STAD

\section{PENDAHULUAN}

$\mathrm{P}$ roses pembelajaran yang bersifat interaktif dan edukatif perlu melibatkan peserta didik secara aktif agar hasil belajar sebagaimana yang diharapkan dapat dicapai. Oleh sebab itu, guru diharapkan mampu memanfaatkan berbagai model, metode dan media sesuia dengan kebutuhan peserta didik agar materi yang diajarkan bisa dipahami an dikuasai peserta didik secara optimal.

Pemilihan model, metode maupun media pembelajaran yang sesuai dapat menyebabkan siswa tidak merasa bosan dalam proses pembelajaran dan lebih mudah memahami materi yang di pelajarinya. Berdasarkan hasil observasi dan wawancara penulis dengan guru IPA Biologi di SMP N
3 Batang Anai Kabupaten Padang Pariaman, pada bulan November 2016 diperoleh informasi, bahwa rendah-nya hasil belajar IPA Biologi siswa disebabkan oleh beberapa faktor yaitu, pembelajaran masih terpusat pada guru. Penggunaan model pembelajaran dan media yang diterapkan belum tepat oleh guru menjadikan mata pelajaran IPA Biologi kurang menarik, sehingga dalam proses pembelajaran partisi-pasi siswa dalam bertanya masih kurang dan siswa sulit memahami materi.

Salah satu materi yang dianggap sulit dipahami oleh siswa kelas VIII IPA Biologi adalah materi system gerak pada manusia, karena materi ini siswa dituntut memahami dan menjelaskan bagian-bagian sendi, otot serta gangguan yang terjadi pada materi 
system gerak pada manusia. Hal ini menyebabkan hasil belajar IPA Biologi yang diperoleh siswa masih rendah.

Keadaan ini menunjukkan bahwa proses pembelajaran IPA Biologi belum memperoleh hasil yang optimal, maka pemilihan model, metode, dan media pembelajaran yang tepat akan dapat meningkatkan motivasi dan keaktifan siswa. Salah satunya metode pembelajaran seperti ini adalah model pembelajaran kooperatif tipe Student Teams Achievenment Division (STAD), yang tujuannya adalah mendorong agar peserta didik saling bantu dalam menguasai skill yang diajarkan kepada mereka (Rusman (2014: 214).

Menurut Lufri (2007:48-49) langkahlangkah model STAD meliputi uji awal, pengelompokan peserta didik berdasarkan prestasi (1 kelompok belajar siswa terdiri dari empat sampai lima orang.), jenis kelamin dan lain-lain, penjelasan materi oleh guru, dan pemberian kuis oleh guru yang diikuti oleh seluruh peserta didik. Guru menyajikan pelajaran atau melakukan presentasi verbal atau teks. Selanjutnya, siswa diminta untuk bekerja berkelompok dengan menggunakan lembaran kegiatan atau perangkat pembelajaran lainnya agar peserta didik bisa menguasai materi dengan tuntas. Selain itu, siswa juga diberi kuis untk mengetahui perkembangan masing-masing individu. Dari skor yang didapatkan, skor perkembangan masing-masing siswa dibandingkan dengan skor rata-rata pre-test). Untuk mendapatkan skor kelompok, skor yang diperoleh oleh masing-masing individu siswa dijumlahkan. Bagi kelompok dengan prestasi terbaik sebagaimana yang ditargetkan diberi penghargaan.
Pembelajaran STAD memiliki beberapa kelebihan dan kekurangan. Kelebihan model pembelajaran STAD menurut (Istarani 2014:28-29) adalah 1) Dapat meningkatkan kerjasama diantara siswa. Karena mereka saling bekerjasama dalam kelompok. 2) Dapat memupuk rasa kebersamaan dan keberagaman dalam perbedaan. karena, dalam kelompok terdiri dari anggota yang heterogen. 3) Keutamaannya dapat digunakan dalam pengajaran mengajarkan materi-materi ilmu pasti. 4) Dengan kuis dapat menye-nangkan anak dalam menjawab soal-soal materi yang diajarkan, 5) dapat mengetahui kemampuan anak secara cepat. 6) Dengan pemberian reward akan mendorong atau memotivasi siswa-siswa untuk lebih giat belajar, serta dengan adanya reward akan memberikan nuansa persaingan sehat di antara siswa.

Sedangkan kekurangannya adalah 1) adanya siswa yang tidak akur dalam kelompoknya, karena ia dikelompokan pada anggota yang kurang ia senang ia tau sukai. 2) Dalam kelompok, adanya siswa yang hanya sebagai pendengar budiman, kurang aktif. Ia beranggapan tugas akan selesai dikerjakan oleh temannya. 3) Kuis kurang dapat mengetahui aspirasi siswa yang lambat dalam berfikir, karena dalam kuis dibutuhkan kecepatan dan kecermatan. 4) Pemberian reward adakalanya tidak sesuai dengan harapan atau keinginan siswa.

Dalam penerapan model pembelajaran, STAD dapat dikombinasikan dengan berbagai media, misalnya LDS, agar minat belajar peserta didik dapat ditumbuhkan. LDS merupakan salah satu media cetak yang digunakan untuk membantu dan mempermudah dalam kegiatan proses pembelajaran STAD. Penggunaan LDS pada 
model pembelajaran STAD ini bertujuan supaya siswa dapat mengetahui secara jelas dari materi sistem gerak pada manusia dengan diskusi kelompok. Proses pembelajaran dengan menggunakan model pembelajaran Tipe STAD disertai Lembar Diskusi Siswa (LDS) juga berfungsi sebagai arahan (petunjuk) pada saat diskusi dan juga dapat membantu meningkatkan cara belajar siswa aktif, dan memotivasi siswa agar tidak mudah bosan dalam mengikuti proses pembelajaran.

Berdasarkan uraian permasa-lahan di atas maka penulis telah melakukan penelitian dengan judul " Penerapan Model Pembelajaran Kooperatif Tipe STAD Disertai LDS Terhadap Hasil Belajar IPA Biologi Siswa Kelas VIII SMP N 3 Batang Anai Kabupaten Padang Pariaman Pada Ranah Kognitif ". Penelitian ini bertujuan untuk mengetahui hasil belajar siswa kelas VIII SMP N 3 Batang Anai dengan penerapan model pembela-jaran kooperatif tipe $S T A D$ disertai LDS pada ranah kognitif.

Hipotesis dalam penelitian ini adalah.

Ho: Tidak terdapat peningkatan hasil belajar siswa kelas VIII SMP N 3 Batang Anai dengan penerapan model pembelajaran kooperatif tipe $S T A D$ pada ranah afektif, kognitif dan psikomotor.

H1: Terdapat peningkatan hasil belajar siswa kelas VIII SMP N 3 Batang Anai dengan penerapan model pembelajaran kooperatif tipe $S T A D$ pada ranah afektif, kognitif dan psikomotor.

\section{METODE PENELITIAN}

Penelitian ini dilaksanakan di SMP N 3 Batang Anai Kabupaten Padang Pariaman pada bulan Juli-Agustus 2017 semester ganjil tahun pelajaran 2017/2018.
Rancangan penelitian yang digunakan dalam penelitian ini adalah Randommized Control-Group Posttest Only Design. Secara umum prosedur penelitian dibagi atas 3 tahap, yaitu:

\section{Tahap Persiapan}

a. Mempersiapkan surat izin penelitian.

b. Menetapkan jadwal pelaksanaan.

c. Menentukan populasi sampel.

d. Memilih dua kelas yaitu kelas eksperimen dan kelas kontrol.

e. Konsultasi dengan guru bersangkutan.

f. Menentukan pembagian kelom-pok belajar berdasarkan nilai akademiknya pada kelas eksperimen.

g. Mempersiapkan Silabus, Rencana Pelaksanaan Pembelaja ran (RRP) dan Lembar Diskusi Siswa (LDS).

h. Melakukan Pra penelitian

i. Mempersiapkan sumber-sumber dan bahan yang diperlukan untuk mendukung pembelajaran model kooperatif tipe Student Teams Achievenment Division (STAD) disertai LDS.

j. Mempersiapkan soal Pretest dan postest yang diberikan..

k. Membuat kisi-kisi soal tes hasil belajar.

1. Menyusun soal-soal tes hasil belajar.

m. Melakukan uji coba soal

\section{Tahap Pelaksanaan}

Pelaksanaan penelitian ini merupakan pemberian perlakuan selama proses pembelajaran. Perlakuan yang diberikan berbeda antara kelas eksperimen dengan kelas kontrol. Kelas eksperimen mengguna kan model pembelajaran STAD disertai LDS, sedangkan kelas kontrol menggunakan metode diskusi dan tanya jawab. 
Instrumen penelitian yang dilakukan pada ranah kognitif menggunakan soal yang diberikan melalui tes tertulis diakhir penelitian dengan bentuk objektif sebanyak 55 butir soal.

\section{Validitas Soal}

Sebuah soal dikatakan sahih atau valid jika soal itu mengukur secara tepat apa yang semestinya diukur (Arikunto, 2010:73). Dengan kata lain, sebuah soal adalah valid bila soal itu mengukur sesuai dengan materi yang telah diajarkan. Validas jenis ini disebut validitas kurikuler karena materi yang diajarkan dimuat di dalam kurikulum. Untuk mengukur validitas isi sebuah soal bisa digunakan korelasi Product Moment dengan simpangan sebagai berikut :

$$
r_{x y}=\frac{\sum x y}{\sqrt{\left(\sum_{x} 2\right)\left(\sum_{y} 2\right)}}
$$

Keterangan:

$\mathrm{r}_{\mathrm{xy}}=$ Koefisien korelasi antara variabel $\mathrm{X}$ dan variabel $\mathrm{Y}$, dua variabel yang dikolerasikan.

$\sum \mathrm{xy}=$ Jumlah perkalian $\mathrm{X}$ dan $\mathrm{Y}$.

$x^{2}=$ Kuadrat dari X (tes uji coba)

$y^{2}=$ Kuadrat dari Y (tes sebelum uji coba)

Kriteria koefisien validitas sebagai berikut:

0,800-1,00 : Validitas sangat tinggi

$0,600-0,800:$ Validitas tinggi

0,400-0,600 : Validitas cukup

0,200-0,400 : Validitas rendah

$0,00-0,200:$ Validitas sangat rendah

Kriteria validitas yang dipakai berkisar antara $0,400-1,00$

\section{Reliabilitas Tes}

Menurut Arikunto (2010: 90) reliabilitas adalah ketetapan suatu tes apabila diteskan kepada subjek yang sama.
Reliabilitas suatu instrumen dapat di ukur konsistensinya melalui metode-metode tertentu. Menurut Arikunto (2010: 103) rumus reliabilitas yang digunakan adalah $K-R 21$ :

$$
r_{11}=\left[\frac{n}{n-1}\right]\left[1-\frac{M(n-M)}{n S_{t}^{2}}\right]
$$

Keterangan:

$\mathrm{r}_{11}=$ Reliabilitas tes secara keseluruhan.

$\mathrm{n}$ = Jumlah butir soal.

$\mathrm{M}=$ Skor total/rata-rata skor soal

$\mathrm{S}_{\mathrm{t}}^{2}=$ Varians tes

$\mathrm{S}=$ Standar deviasi

Dengan kriteria reliabilitas:

0,800-1,00 : Sangat tinggi.

$0,600-0,800 \quad$ : Tinggi.

0,400-0,600 : Sedang.

0,200-0,400 : Rendah

0,00-0,200 : Sangat rendah.

Tingkat kriteria reliabilitas yang dinyatakan baik dengan rentang 0,400-1,00.

\section{Daya Pembeda Soal (D)}

Sudijono (2011:385-386) menyatakan bahwa daya pembeda atau indeks diskriminasi (D) adalah kemampuan suatu butir item soal atau tes untuk membedakan antara peserta didik yang mempunyai kemampuan tinggi dengan yang mereka yang mempunyai kemampuan rendah.

Menurut Sudijono (2011:389-390), rumus untuk mengetahui besar kecilnya indeks diskriminasi adalah:

$$
\mathrm{D}=\frac{\mathrm{BA}}{\mathrm{JA}}-\frac{\mathrm{BB}}{\mathrm{JB}}=P A-P B
$$

Keterangan:

$\mathrm{D}=$ Angka indeks diskriminasi item.

$\mathrm{P}_{\mathrm{A}}=$ Proporsi testee kelompok atas yang dapat menjawab dengan benar

$\mathrm{P}_{\mathrm{B}}=$ Proporsi testee kelompok bawah yang dapat menjawab dengan benar 
$\mathrm{B}_{\mathrm{A}}=$ Banyaknya testee kelompok atas yang dapat menjawab dengan benar.

$\mathrm{B}_{\mathrm{B}}=$ Banyaknya testee kelompok bawah yang dapat menjawab dengan benar.

$\mathrm{J}_{\mathrm{A}}=$ Jumlah testee yang termasuk dalam kelompok atas.

$\mathrm{J}_{\mathrm{B}}=$ Jumlah testee yang termasuk dalam kelompok bawah.

Klasifikasi daya pembeda yaitu:

$\begin{array}{ll}>0,20 & \text { : Jelek } \\ 0,20-0,40 & \text { : Sedang. } \\ 0,40-0,70 & \text { : Baik. } \\ 0,70-1,00 & \text { : Baik sekali. } \\ \text { Minus } & \text { : Jelek sekali. }\end{array}$

Kriteria soal yang dipakai pada daya pembeda adalah 0,20-1,00.

\section{Indeks Kesukaran Soal (P)}

Untuk mendapatkan indeks kesukaran data digunakan rumus yang dikemukakan oleh Witheringtone (1998) dalam Sudijono (2011: 372).

$$
P=\frac{B}{J S}
$$

\section{Keterangan:}

$\mathrm{P}=$ Angka indeks kesukaran item.

$\mathrm{B}=$ Banyaknya siswa yang menjawab soal itu dengan benar.

JS = Jumlah seluruh siswa peserta tes.

Kriteria indek kesukaran sebagai berikut :

IK $<0,25=$ Soal terlalu sukar.

$0,25-0,75=$ Soal cukup (sedang).

IK $>0,75=$ Soal terlalu mudah.

Kriteria yang dipakai dalam indek kesukaran item berkisar 0,25-0,75.

\section{HASIL DAN PEMBAHASAN}

Berdasarkan hasil penelitian pada kedua kelas sampel dengan memberikan tes akhir dalam bentuk soal pilihan ganda sebanyak 55 soal pada materi sistem gerak manusia didapat bahwa nilai rata-rata kelas eksperimen lebih tinggi dari kelas kontrol (Gambar 1).

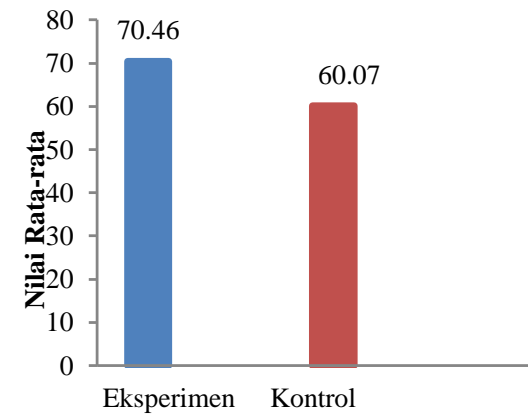

Gambar 1. Grafik Nilai Rata-Rata Ranah Kognitif Kelas Sampel

Berdasarkan (Gambar 1). dapat dilihat bahwa nilai rata-rata hasil belajar IPA Biologi siswa pada kelas eksperimen dengan penerapan model pembelajaran kooperatif tipe $S T A D$ disertai LDS rata-rata nilai kognitif kelas eksperimen lebih tinggi dibandingkan kelas kontrol yaitu kelas eksperimen 70.46 dan kelas kontrol 60.07.

Pada ranah kognitif ini didapatkan hasil uji normalitas kelas eksperimen diperoleh bahwa $\mathrm{L}_{0}=0.13565$ dan $\mathrm{L}_{\text {tabel }}=0.167$ berarti $\mathrm{L}_{0}<\mathrm{L}_{\text {tabel }}$ bahwa hasil belajar siswa berdistribusi normal. Sedangkan data uji normalitas kelas kontrol diperoleh bahwa $\mathrm{L}_{0}=0.0895$ dan $\mathrm{L}_{\text {tabel }}=0.1849$ berarti $\mathrm{L}_{0}<\mathrm{L}_{\text {tabel }}$ bahwa hasil belajar siswa berdistribusi normal. Artinya hasil uji normalitas kedua kelas sampel berdistribusi normal.

Kedua kelas sampel mempunyai varians homogen, hal ini dapat dilihat dari hasil uji homogenitas dengan hasil uji $F_{\text {hitung }}(1,55)$ dan $F_{\text {tabel }}(1,97)$ berarti pada taraf 0,05 dengan dk 27,22 berarti $F_{\text {hitung }}<F_{\text {tabel }}$ bahwa kedua kelas sampel mempunyai varians yang homogen. Karena populasi berdistri-busi normal dan mempunyai varians yang homogen maka dilakukan uji t untuk melihat apakah hipotesis diterima atau ditolak. 
Berdasarkan hasil uji hipotesis didapatkan hasil pada taraf nyata 0.05 didapat $t_{\text {tabel }}$ (1.68) sedangkan $t_{\text {hitung }}$ (2.11) berarti $t_{\text {hitung }}>t_{\text {tabel }}$ dengan demikian hipotesis $\mathrm{H}_{1}$ diterima yang berarti terjadi peningkatan hasil belajar ranah kognitif pada kelas sampel, tetapi walaupun secara statistik hipotesis diterima namun belum memberikan perubahan pada pengetahuan siswa jika dilihat dari predikat kedua kelas sampel cukup. Hal ini disebabkan selama proses pembelajaran siswa kurang memperhatikan materi sehingga belum memberi peningka tan pada ranah kognitif.

Penilaian ranah kognitif diambil dari nilai tes akhir yang dilakukan pada akhir pembelajaran. Tes akhir ini menggunakan 55 soal pilihan ganda yang telah diambil dari 110 soal yang telah di uji cobakan pada kelas VIII.1 yang bukan kelas sampel. Adapun nilai rata-rata kelas eksperimen dan kelas kontrol dapat dilihat pada (Gambar 1). Hal ini dapat dilihat dari ketuntasan pada kelas eksperimen yang menggunakan model pembelajaran kooperatif tipe STAD disertai LDS siswa yang tuntas sebanyak 14 siswa dari 28 orang siswa dengan ketuntasan uji $50 \%$. Sedangkan pada kelas kontrol siswa yang tuntas sebanyak 5 siswa dari 23 orang siswa dengan ketuntasan $22 \%$ pada kelas kontrol yang menggunakan metode diskusi dan tanya jawab. Menurut Djamarah dan Zain (2013:107) bahwa dikatakan baik apabila bahan pelajaran yang diajarkan hanya $60 \%$ s.d $75 \%$ dikuasai oleh siswa dan dikatakan kurang apabila bahan pelajaran yang diajarkan kurang dari $60 \%$ dikuasai oleh siswa.

Nilai rata-rata keseluruhan kelas sampel sama-sama mendapat-kan nilai predikat cukup, kelas eksperimen dengan presentase ketuntasan $50 \%$ dan pada kelas kontrol dengan presentase ketuntasan $22 \%$. Hal ini disebabkan karena siswa kelas eksperimen dan kelas kontrol sama-sama sudah mengikuti arahan dari guru sehingga mendo-rong siswa menjadi aktif dan bekerja sama dalam proses pembelajaran.

Pada kelas eksperimen dengan menggunakan penerapan pembelaja ran kooperatif tipe STAD disertai LDS dimana dengan model ini dapat meningkatkan kerjasama diantara siswa karena mereka saling bekerja sama dalam kelompok, dengan memupuk rasa kebersamaan dalam perbedaan karena dalam kelompok terdiri dari anggota yang heterogen, dengan adanya pretest dan postest dapat menyenangkan siswa dalam menjawab soal-soal materi yang diajarkan dan dapat mengetahui kemampuan siswa secara cepat, dengan pemberian reward akan mendorong atau memotivasi siswa untuk lebih giat belajar dan dengan adanya reward akan memberikan nuansa persaingan sehat antara siswa. Hal yang sama juga telah dilakukan oleh Indriati, dkk. (2015) bahwa dengan menggunakan model STAD hasil belajar peserta didik pada siklus pertama meningkat sebesar 52\% dan pada siklus kedua meningkat sebesar $83 \%$.

Menurut Hamalik (2011:33) minat belajar siswa timbul apabila siswa tertarik akan sesuatu yang dipelajari dan dirasakan bermakna baginya, meningkatakan minat belajar siswa, membuat siswa aktif dalam proses pembelajaran, sesuai pernyataan Slameto (2010:12) agar setiap siswa berpatisipasi aktif dalam proses 
pembelajaran minatnya perlu ditingkatkan terlebih dahulu.

Hasil penelitian menunjukkan bahwa kelas kontrol yang diajar dengan menggunakan metode ceramah dan metode tanya jawab memiliki hasil yang lebih rendah dari kelas eksperimen yang menerapkan model pembelajaran kooperatif tipe $S T A D$ dapat dilihat pada (Gambar 1). Rendahnya hasil belajar siswa disebabkan karena pada kelas kontrol proses pembelajarannya hanya menggunakan metode diskusi dan tanya jawab, disini guru memberikan tugas kepada siswa dan meminta siswa untuk mengerjakannya, sehingga siswa kurang termotivasi dalam mengikuti proses pembelajaran.

Hal ini terlihat juga pada saat guru menjelaskan mata pelajaran hanya beberapa siswa yang memper hatikan sedangkan siswa yang lain sibuk dengan hal-hal lain seperti bercerita dengan teman sebelahnya dan melakukan kegiatan yang lain yang tidak bersangkutan dengan pelajaran. Dalam hal ini guru sudah berupaya untuk menegurnya agar tidak meribut saat jam pelajaran berlangsung, siswa tersebut ada mendengarkan apa yang ditegur oleh guru tetapi tidak lama kemudian mereka mengulangi perbuatannya.

Menurut Djamarah (2010:97) bahwa kelemahan dari metode ini bila digunakan atau terlebih lama akan membosankan bagi siswa," sehingga siswa kurang aktif dan kurang termotivasi dalam mengikuti proses pembelajaran, sehingga siswa lebih sering ribut.

\section{KESIMPULAN}

Hasil penelitian menunjukkan bahwa model pembelajaran kooperatif tipe STAD disertai LDS dapat meningkatkan hasil belajar siswa kelas VIII IPA Biologi SMP N 3 Batang Anai Kabupaten Padang Pariaman.

\section{REFERENSI}

Aswar, Syafri. (2009). Penilaian Berbasis Kompetensi, Padang : UNP Press.

Djamarah dan Zain (2013). Strategi Belajar Mengajar. Jakarta : Rineka Cipta

Hamalik, O. (2013). Kurikulum dan Pembelajaran. Jakarta: Bumi Aksara.

Indriati, G. ; E Rosba , R .Kasmeri (2015). Upaya Peningkatan Aktivitas dan Hasil Belajar Mahasiswa Melalui Mind Map dengan Model Pembe lajaran Kooperatif Tipe STAD pada mata kuliah Anatomi Fisiologi Manusia. Jurnal Ta'dib, Vol 18 No 2 Desember 2015.

Latisma. J. (2011). Evaluasi Pendidikan. Padang: FMIPA UNP

Lufri. (2007). Strategi Pembelajaran Biologi. Padang: UNP Press.

Rusman. (2014). Model-Model Pembelajaran. Jakarta: Raja Grafindo Persada.

Sardiman. (2011). Interaksi dan Motivasi Belajar Mengajar. Jakarta: Rajawali Pers

Slameto. (2010). Belajar dan Faktor-Faktor yang Mempengaru -hinya. Jakarta: Rineka Cipta 
Sudijono, Anas. (2011).Pengantar Evaluasi Pendidikan. Jakarta: Raja Grafindo Persada.
Kunandar. (2013). Penilaian Auntentik.. Jakarta: Raja Wali

\section{Article Metadata:}

Indriati, G. Rosba, E. Mely, T.J. (2018). The Impact of STAD Type Cooperative Learning on Students' Learning Achievement at SMPN 3 Batang Anai Pariaman. Ta'dib, 21 (1), 6168.

http://dx.doi.org/10.31958/jt.v21i1.1047

Keywords: Activity, Learning outcomes, Cooperative learning model type STAD

Coresponding author: Gustina Indriati, STKIP PGRI Sumbar, gustinaindriati@yahoo.com 